\title{
Analysis of Nip Mechanics Model for Rolling Calender Used in Textile Industry
}

\author{
N. Gupta ${ }^{1}$, N. Kanth ${ }^{2 *}$ \\ ${ }^{1}$ Research Scholar, Department of Mathematics, Jaypee University of Information Technology, \\ Waknaghat, Solan (H.P.), India \\ e-mail: shah.neelam28@yahoo.in \\ ${ }^{2}$ Assistant Professor, Department of Mathematics, Jaypee University of Information \\ Technology, Waknaghat, Solan (H.P.), India \\ e-mail: neelkanth28@gmail.com \\ *corresponding author
}

\begin{abstract}
Calendering is programmed finishing technique in the textile industry where the texture is squeezed between two or more rolls with a goal to obtain desired fragile quality, radiance and translucency. The essential guideline of calendering is to open the material to the joined impact of dampness, warmth and weight until the point texture gains an extraordinarily smooth and light reflecting surface. The essential mechanical action of the rolling calender is to cause the fibers of the web to reshape and deform around one another to get the desired smoothness. In this examination, an attempt has been made to develop a non-Hertzian nip mechanics model for finding the contact width of rolling calender and simulate this model to explore the impacts of design and process parameters such as load applied, bulk modulus, bonding time, diameter of the roll and cover thickness on contact width.
\end{abstract}

Keywords: Bulk modulus, Nip Mechanics, Contact Mechanics, Non-Hertzian contact, Bonding time, Contact width

\section{Introduction}

Calendering is a finishing method from which thin film materials like paper, rubber, plastics and textile are pressed into sheets of the smooth, clear, graceful and imprinted surfaces. In textile industry, it is a quick squeezing strategy which essentially gives radiance and is generally the last treatment for the textures in the completing succession. The final decoration of texture is to improve the value and sale request. Textile finishing is a name which is normally used for a variety of processes that the textile materials go through after completing the bleaching and printing process. There are various advantageous properties that are similar to crease recovery, luster, softness, dimensional stability, drape and so on, which are imparted to textile material mostly by finishing treatments (Osswald and Hernández-Ortiz 2006). Finishing processes are needed for high sales request, high wear worth, extraordinary effects, console and body safety which reports good-looking form, enough tensile along with graze strengths, dimensional 
solidity, wrinkle recovery and liberty from pilling, right heat insulation, humidity absorption, air permeability and water repellency (Hall 1966, Osswald and Hernández-Ortiz 2006).

Calendering is the final view point for influencing these properties in texture formation of numerous rating of the textile. In the process of calendering, the substrate is pressed between two or more rolls (Hall 1966, Jokio 1999). Calendering is a high speed ironing process which firstly imparts luster that is the final pre-treatment of the textures in the final cycle (Kanth et al. 2016). The fundamental rule of calendering is to portrayal the texture with the combined impact of dampness, warmth, and weight until the point when the textured surface turns out to be extremely smooth and light and obtains good quality luster (Hall 1966, Kopitar et al. 2014). Generally, calendering unit is an assembly of hard rolls having a covering of chilled cast iron, or alternate hard and soft rolls mounted in vertical frames (Jokio 1999). The rolls vary from 2 to 10 rolls and these rolls are praise with respect to allow some gas fire which helps rolls to heat at two different temperatures (Jokio 1999). The effects of the calendering process are temporary on the texture and fade away after the first washing. Semi-permanent luster is obtained through wadding texture in a careful suspension of soluble polyvinyl acetate prior to calendering where this solution is working as a binding agent (Kopitar et al. 2014, Osswald and Hernández-Ortiz 2006). Also, the permanent finish can be obtained by treating texture through groove recovery reagent solution followed by calendering and therapeutic of the texture at a temperature near about $150^{\circ} \mathrm{C}$ (Bhat et al. 2004, Hall 1966).

Smoothness and gloss of the texture depend upon the temperature of the rolls and texture, linear load applied, bonding time, the speed of roll, soft roll material and a number of nips (Enomae et al. 1997, Kanth et al. 2016). The smoothness and gloss of substrate expanded with the increment in the hardness of the roll, as harder roll do not deform in nip width area. When the temperature of hard roll and number of nips is increased then gloss generated more rapidly in contrast with smoothness (Peel 1991, Zhu et al. 2018). For the preparation of calendering, texture is folded by the front side, face side or inside with the lengthwise and stitched along the edges (Bhat et al. 2004, Kopitar et al. 2014). To make texture smoother and more lustrous, it is passed through rollers with high temperature and pressure that polish the surface and make texture smoother and more lustrous (Bhat et al. 2004, Zhu et al. 2018). The web that goes through the calendering process gives thin, glossy and papery surface (Bhat et al. 2004).

The contact width depends on the applied linear load, radius and bulk modulus of the rolls in contact. Subsequently, the contact width plays a crucial role because it affects the quality of the texture (Kanth et al. 2014). In the present study, Meijers model has been modified to make it applicable to the calendering process in textile industries. The mathematical model developed for calculating contact width of rolling calender used in textile industry shows that contact width depends on a variety of process and design parameters of the rolling calender. The model developed in this paper is based on the supposition that the classical linear theory of elasticity applies to our contact problem which suggests that the ratio of half of the contact width to the radius is less than unity (Johnson 1985, Meijers 1968).

\section{Rolling Calendering Process}

The Rolling Calender is applicable to all types of textures. The rolling calendering unit is a stack of two to five rolls with alternative hard and soft rolls. Rolling calender containing three rolls is mainly used for cotton fabrics to improve the drapery, gloss and smoothness of the fabric. It consists of double row spherical rollers, with bottom loading. It has additional oil circulating system used for roll heating system which distinguishes it from others. The hard rolls are having a covering of chilled cast iron while soft rolls are having a covering of wool felt papers, khaki wool, cotton and cotton blends which help in the extension of the webs (Hall 1966, Jokio 1999). 
Hard rolls are run through a variable speed motor, either directly or through a roller chain drive whereas the soft roll runs through off nip drive. The hard rolls can be heated by gas, hot oil, electric or steam when needed up to $210^{\circ} \mathrm{C}$. The main function of the rolling calender is to reshape and flattens the webs as it causes the webs to nestle or more tightly stack around one another. All fabrics undergo rolling calender process for acquiring gloss and smoothness. The effect of rolling calender on gloss and smoothness is highly influenced by the basic parameters involved in the calendering process (Sorvari and Parola 2014).

\section{Hertz and Meijers Nip Mechanics Model}

Now a days, nip mechanics is used in various fields of textile industry, especially in the calendering process to a greater extent (Sorvari and Parola 2014). Nip mechanics i.e. the speculations of rolling contact mechanics is necessary for a variety of calender geometries (Kanth et al. 2016). The benchmark solution for calculating nip width for two homogeneous bodies in contact was firstly given by Hertz (Johnson 1982). The second most important benchmark solution was given by Meijers for rigid cylinder indenting on an elastic layer (Johnson 1982, Meijers 1968). Hertz model is based on several assumptions. The two major assumptions are, contacting bodies are continuous and there is frictionless contact between isotropic flexible bodies and contact length is less when compared with the relative radii of curvature of cylinders (Johnson 1982, Solanki and Vakharia 2017a).

The contact width for two homogeneous cylindrical bodies in contact according to Hertz is given by (Johnson 1982, Kanth et al. 2016).

$$
A=2 \sqrt{\left(\frac{2 L D_{E}}{\pi E^{*}}\right)}
$$

where $A$ is the contact width, $L$ is the load applied, $D_{E}$ is the equivalent diameter and $E^{*}$ is the equivalent bulk modulus.

The equivalent diameter $D_{E}$ for two cylindrical bodies in contact is given by (Kanth et al. 2014, Liu et al. 2005)

$$
\frac{1}{D_{E}}=\frac{1}{D_{1}}+\frac{1}{D_{2}}
$$

where $D_{1}$ and $D_{2}$ are the diameters of two cylindrical rolls in contact with each other.

Also, the equivalent bulk modulus $E^{*}$ of two cylindrical rolls in contact is given by (Dintwa et al. 2008, Kogut and Etsion 2002, Liu et al. 2005, Rodal 1989)

$$
\frac{1}{E^{*}}=\frac{1-v_{1}^{2}}{E_{1}}+\frac{1-v_{2}^{2}}{E_{2}}
$$

where $E_{1}, E_{2}$ is the bulk modulus and $v_{1}, v_{2}$ are Poisson's proportion of two cylindrical rolls in contact respectively.

when $E_{1}>E_{2}$, equation (3) can be rewritten as 


$$
\frac{1}{E^{*}}=\frac{1-v^{2}}{E_{2}}
$$

Hertz had not well thought-out in his nip mechanics model about the cover thickness $t$ of the cylinder. Therefore when the cover thickness $t$ is generously proportioned to a greater extent than the half contact width, only then the half-space presumption is legitimate and fulfilling the disparity $\frac{(A / 2)}{t} \leq \frac{1}{4}$. If this ratio is greater than 2 , then half space assumption will lead to gross under estimation of the contact stresses (Naghieh et al. 1999).

The solution from Hertz's is most famous and commonly used for contact mechanics to make contact among two elastic bodies. The applications of Hertz model are limitless. Still it has certain limitations (Darji and Vakharia 2013, Solanki and Vakharia 2017b). The consideration of nonconformal spheres contact are the major limitations of this solution as ideally the body profile might be complex. But he does not consider when the cross sections of two bodies are multiply connected (Fu 2007, Solanki and Vakharia 2017b).

The solution given by Hertz is not extremely applicable to practical calendering nevertheless considered for very basic cases. This solution does not give good results if the rolls which are in contact have a covering of delicate material like chilled cast iron, rubber and nylon etc., known as non-Hertzian contact (Johnson 1985) as shown in Figure 1.

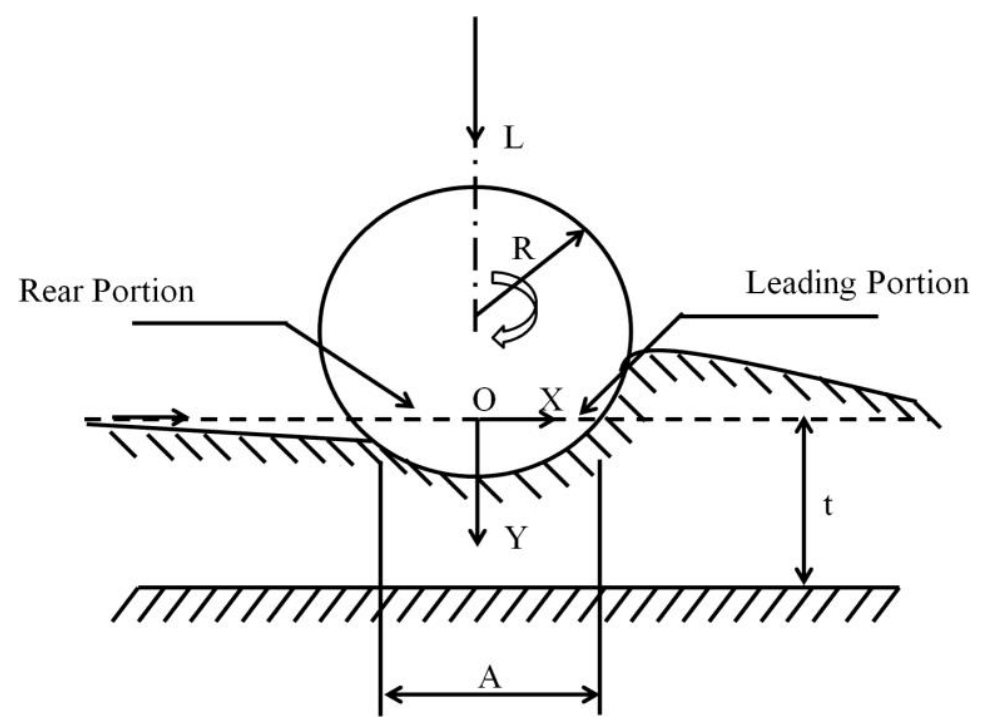

Fig. 1. The geometry of the problem

We are principally paying attention to find the contact width for rolling calender where the hard roll is having covering of chilled cast iron and soft roll is a cotton filled roll. These rolls are in contact with their axis parallel to each other. Meijers (Meijers 1968) also worked on the nip mechanics model where contact width of the cylinder is smaller than its radius. Figure 1 demonstrates the geometry of the problem where the unbending roll is getting in touch with a flexible layer having thickness $t$ appended to a firm base. This is proportional to the contact of two non-homogeneous rolls where one roll is having covering of thickness $t$ (Meijers 1968). 
It is taken to be true that cylinder is adequately long to make plane deformation in light of the fact that there is no contact among layer and the cylinder. Area of contact measured in a longitudinal direction from end to end is greatly sized when contrasted with the distance of the area of contact from side to side. Thus level surface gets firmly extended and plain strain equations can be applied (Kanth et al. 2014).

\section{Formulation of Nip Mechanics Model for Rolling Calender (NMMR)}

The pressure distribution given by Meijers in his paper is (Meijers 1968)

$$
L(z)=\sum_{j=0}^{\infty} L_{j}(z)\left(\frac{A}{2 t}\right)^{2 j}
$$

Equation (5) can be expanded in the form

$$
L(z)=L_{0}(z)+L_{1}(z)\left(\frac{A}{2 t}\right)^{2}+L_{2}(z)\left(\frac{A}{2 t}\right)^{4}+\ldots
$$

Also, the recurrent system of integral equations given by Meijers for the system of two rolls in contact in his paper is (Meijers 1968)

$$
\begin{gathered}
\int_{-1}^{1} \frac{L_{0}(\zeta)}{z-\zeta} d \zeta=\frac{\pi E}{2\left(1-v^{2}\right)} \frac{A}{2 R} z \\
\int_{-1}^{1} \frac{L_{j}(\zeta)}{z-\zeta} d \zeta=\frac{1}{2} \sum_{k=1}^{j} k \alpha_{k} \int_{-1}^{1} L_{j-k}(\zeta)\left(\frac{z-\zeta}{2}\right)^{2 k-1} d \zeta
\end{gathered}
$$

The requirement that the pressure remains at the ends of the contact area ensures that equations have unique solution. Therfore, on solving the recurrent system of integral equations using numerical integration and restricting upto $j=2$, we obtain

$$
\begin{gathered}
L_{0}(z)=\frac{\pi E A \sqrt{1-z^{2}}}{4\left(1-v^{2}\right) R} \\
L_{1}(z)=\frac{\pi E A \sqrt{1-z^{2}}}{4\left(1-v^{2}\right) R}\left(\frac{1}{8}\right) \alpha_{1} \\
L_{2}(z)=\frac{\pi E A \sqrt{1-z^{2}}}{4\left(1-v^{2}\right) R}\left(\frac{1}{64}\right)\left(\alpha_{1}^{2}+5 \alpha_{2}+4 \alpha_{2} z^{2}\right)
\end{gathered}
$$

Substituting values of $L_{0}(z), L_{1}(z), L_{2}(z)$ from equations (9), (10) and (11) in equation (6), we have (Mahmoud et al. 2013) 


$$
\begin{aligned}
L(z)=\frac{\pi E A \sqrt{1-z^{2}}}{4\left(1-v^{2}\right) R}+\frac{\pi E A \sqrt{1-z^{2}}}{4\left(1-v^{2}\right) R}\left(\frac{1}{8}\right) \alpha_{1}\left(\frac{A}{2 t}\right)^{2}+ & \\
& \frac{\pi E A \sqrt{1-z^{2}}}{4\left(1-v^{2}\right) R}\left(\frac{1}{64}\right)\left(\alpha_{1}^{2}+5 \alpha_{2}+4 \alpha_{2} z^{2}\right)\left(\frac{A}{2 t}\right)^{4}
\end{aligned}
$$

On integrating the pressure distribution $L(z)$ the total load applied $L$ per unit length is given by

$$
L=\int_{-\frac{A}{2}}^{\frac{A}{2}} L(z) d z
$$

After using (12) in (13), the total load applied $L$ per unit length will become

$$
L=\frac{\pi E}{4\left(1-v^{2}\right)} \frac{A^{2}}{4 R}\left[1+\frac{1}{8} \alpha_{1}\left(\frac{A}{2 t}\right)^{2}+\frac{1}{64}\left(\alpha_{1}^{2}+6 \alpha_{2}\right)\left(\frac{A}{2 t}\right)^{4}\right]
$$

where $\alpha_{1}, \alpha_{2}$ are determined by numerical integration for different values of Poisson's ratio and computed by Meijers in his paper (Mahmoud et al. 2013).

As $E_{1}>E_{2}$, utilizing equation (2) and equation (4), equation (14) can be modified as

$$
L=\frac{\pi E^{*}}{2} \frac{A^{2}}{2 D_{E}}\left[1+\frac{1}{8} \alpha_{1}\left(\frac{A}{2 t}\right)^{2}+\frac{1}{64}\left(\alpha_{1}^{2}+6 \alpha_{2}\right)\left(\frac{A}{2 t}\right)^{4}\right]
$$

The equation presents a general model which is suitable for all type of roll and plate contact. The system is very efficient that can be utilized for printing machine, textile, paper, gears and elastohydrodymic lubrication, polymer and bearing etc. The contact among solid cylinder to solid cylinder and the plate to cylinder is very general in the textile industry.

Equation (15) is a general model for a wide range of roll to roll or rolls to plate contact. Equation (15) becomes the Hertz model when $\frac{A}{2 t}=0$.

Poisson ratio plays a vital role in the calendering process which determines the volumetric compressibility of any material. The value of Poisson ratio for an incompressible material is 0.5 whereas the Poisson ratio for the compressible material is comparatively low (Deshpande 1978). In the case of the rolling calender, the Poisson's proportion is taken as 0.48 for the soft rolls (Callister 2007). For the value $v=0.48$, estimations of $\alpha_{1}$ and $\alpha_{2}$ are 7.7938 and -11.7696 (Kanth et al. 2016).

Substituting the values of $\alpha_{1}$ and $\alpha_{2}$ in equation (15), equation (15) becomes

$$
E_{2}=1.959 \frac{L D_{E}}{A^{2}}\left[1+0.2436\left(\frac{A}{2 t}\right)^{2}-0.0096\left(\frac{A}{2 t}\right)^{4}\right]^{-1}
$$


Equation (16) works as nip mechanics model for rolling calenders (NMMR) used in textile industry. This equation can be applied to linear, homogeneous and isotropic contact problem having small deformations (Mahmoud et al. 2013).

Utilizing equation (16), contact width can be calculated when values of $L, t, E_{2}$ and $D_{E}$ are known. The terms containing $\frac{A}{t}$ are the amendment to the Hertz model, considering finite cover thickness.

\section{Computation from nip mechanics model}

The design parameters given in Appendix A are taken into consideration for simulation of a single nip rolling calender. The equivalent diameter and equivalent bulk modulus are computed using equation (2) and equation (4) respectively. The computed equivalent diameter is $210.01 \mathrm{~mm}$ and computed equivalent bulk modulus is $3.132 \mathrm{kN} / \mathrm{mm}^{2}$. The impact of a variety of design and process parameters has been examined by nip mechanics model given by equation (16) and results are then compared with Hertz solution given by equation (1).

\section{Results and Discussion}

\subsection{Impact of the load applied on contact width}

The contact width $A$ is computed for a variety of estimations of the load applied $L$ by utilizing equation (16), on keeping other parameters steady as shown in Table 1 and the graph is plotted for different values of the load applied as demonstrated in Figure 2.

It demonstrates that with increase in load applied and assuming residual parameters constant, contact width increases. The results obtained from the Hertz model is compared with the results obtained by nip mechanics model for rolling calender (NMMR). It is found that NMMR provides better results as compared to the Hertz model which are very near to actual values. With the increase in contact width, bonding time increases. Hence, gloss and smoothness of fabric increase with increase in load applied.

\begin{tabular}{ccc}
\hline $\begin{array}{c}\text { The load applied } \\
(\mathbf{k N} / \mathbf{m m})\end{array}$ & $\begin{array}{c}\text { Hertz model based } \\
\text { contact width } \\
(\mathbf{m m})\end{array}$ & $\begin{array}{c}\text { NMMR based } \\
\text { contact width } \\
(\mathbf{m m})\end{array}$ \\
\hline $\mathbf{0 . 2}$ & 5.845 & 5.765 \\
$\mathbf{0 . 2 5}$ & 6.535 & 6.4226 \\
$\mathbf{0 . 3}$ & 7.1588 & 7.0132 \\
$\mathbf{0 . 3 5}$ & 7.7324 & 7.5516 \\
$\mathbf{0 . 4}$ & 8.2662 & 8.0483 \\
$\mathbf{0 . 4 5}$ & 8.7677 & 8.5110 \\
$\mathbf{0 . 5}$ & 9.2420 & 8.9450 \\
$\mathbf{0 . 5 5}$ & 9.6931 & 9.3546 \\
$\mathbf{0 . 6}$ & 10.1241 & 9.7429 \\
\hline
\end{tabular}

Table 1. Contact width for different values of the load applied 


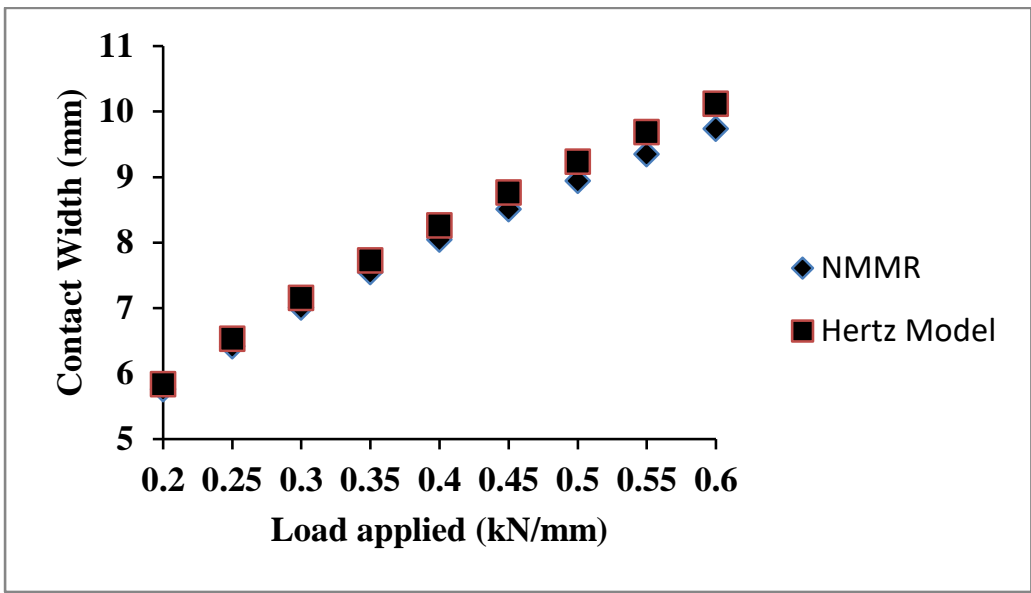

Fig. 2. Impact of the load applied on contact width

\subsection{Impact of equivalent diameter on contact width}

The contact width $A$ is computed for various estimations of equivalent diameter with the constant load applied $0.263 \mathrm{kN} / \mathrm{mm}$ by utilizing equation (16), whereas keeping other parameters constant as shown in Table 2 and the graph is plotted for different values as appeared in Figure 2 .

It demonstrates that with increase in equivalent diameter and assuming residual parameters constant, contact width increases. The results obtained from the Hertz model are compared with the results obtained by nip mechanics model for rolling calender (NMMR). It is found that NMMR provides better results as compared to the Hertz model which are very near to actual results. With the increase in equivalent diameter, contact width and bonding time increases. Hence, gloss and smoothness of fabric increase with increase in equivalent diameter.

\begin{tabular}{ccc}
\hline $\begin{array}{c}\text { Equivalent diameter } \\
(\mathbf{m m})\end{array}$ & $\begin{array}{c}\text { Hertz model based } \\
\text { contact width } \\
(\mathbf{m m})\end{array}$ & $\begin{array}{c}\text { NMMR based } \\
\text { contact width } \\
(\mathbf{m m})\end{array}$ \\
\hline $\mathbf{2 0 0}$ & 6.5413 & 6.4584 \\
$\mathbf{2 5 0}$ & 7.3134 & 7.1924 \\
$\mathbf{3 0 0}$ & 8.0114 & 7.8477 \\
$\mathbf{3 5 0}$ & 8.6533 & 8.4437 \\
$\mathbf{4 0 0}$ & 9.2508 & 8.9940 \\
$\mathbf{4 5 0}$ & 9.8120 & 9.5048 \\
$\mathbf{5 0 0}$ & 10.3427 & 9.9838 \\
\hline
\end{tabular}

Table 2. Contact width for different values of equivalent diameter 


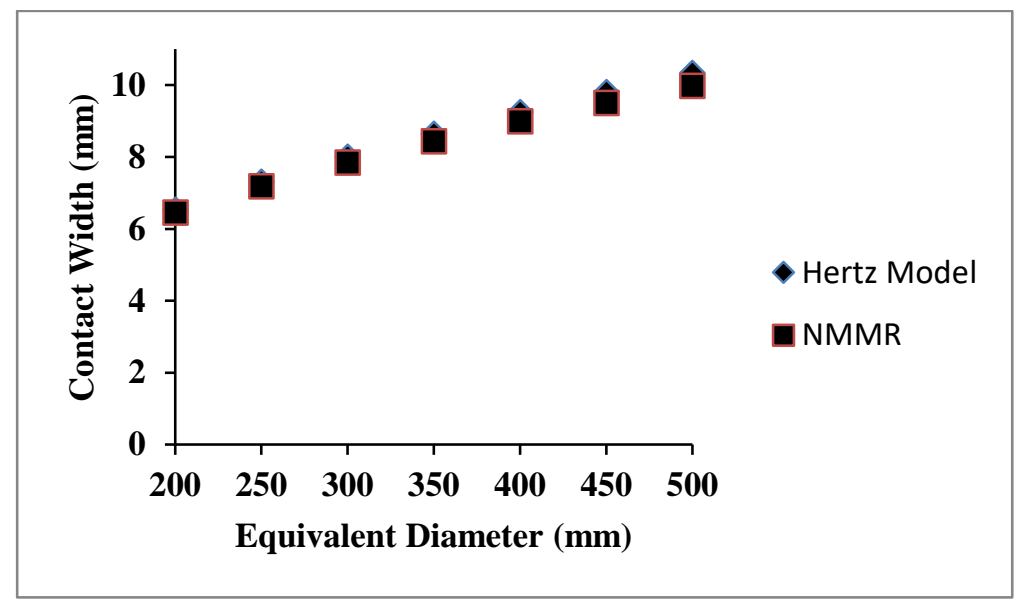

Fig. 3. Impact of equivalent diameter on contact width

\subsection{Impact of equivalent bulk modulus on contact width}

The contact width $A$ is computed for various estimations of equivalent bulk modulus with the constant load applied $0.263 \mathrm{kN} / \mathrm{mm}$ by utilizing equation (16), whereas keeping other parameters constant as shown in Table 3 and the graph is plotted for different values as appeared in Figure 3.

It demonstrates that with increase in equivalent bulk modulus and continuing residual parameters constant, contact width decreases. The results obtained from the Hertz model is compared with the results obtained by nip mechanics model for rolling calender (NMMR). It is found that NMMR provides us with better results as compared to the Hertz model which are very near to actual results. With the increase in equivalent bulk modulus, contact width decreases. Hence, gloss and smoothness of fabric decrease with increase in equivalent bulk modulus.

\begin{tabular}{ccc}
\hline $\begin{array}{c}\text { Equivalent bulk } \\
\text { modulus }\left(\mathbf{k N} / \mathbf{m m}^{2}\right)\end{array}$ & $\begin{array}{c}\text { Hertz model based } \\
\text { contact width } \\
(\mathbf{m m})\end{array}$ & $\begin{array}{c}\text { NMMR based } \\
\text { contact width } \\
(\mathbf{m m})\end{array}$ \\
\hline $\mathbf{3}$ & 6.8486 & 5.9192 \\
$\mathbf{4}$ & 5.9311 & 5.1442 \\
$\mathbf{5}$ & 5.305 & 4.6109 \\
$\mathbf{6}$ & 4.8428 & 4.2152 \\
$\mathbf{7}$ & 4.4835 & 3.9066 \\
\hline
\end{tabular}

Table 3. Contact width for different values of equivalent bulk modulus 


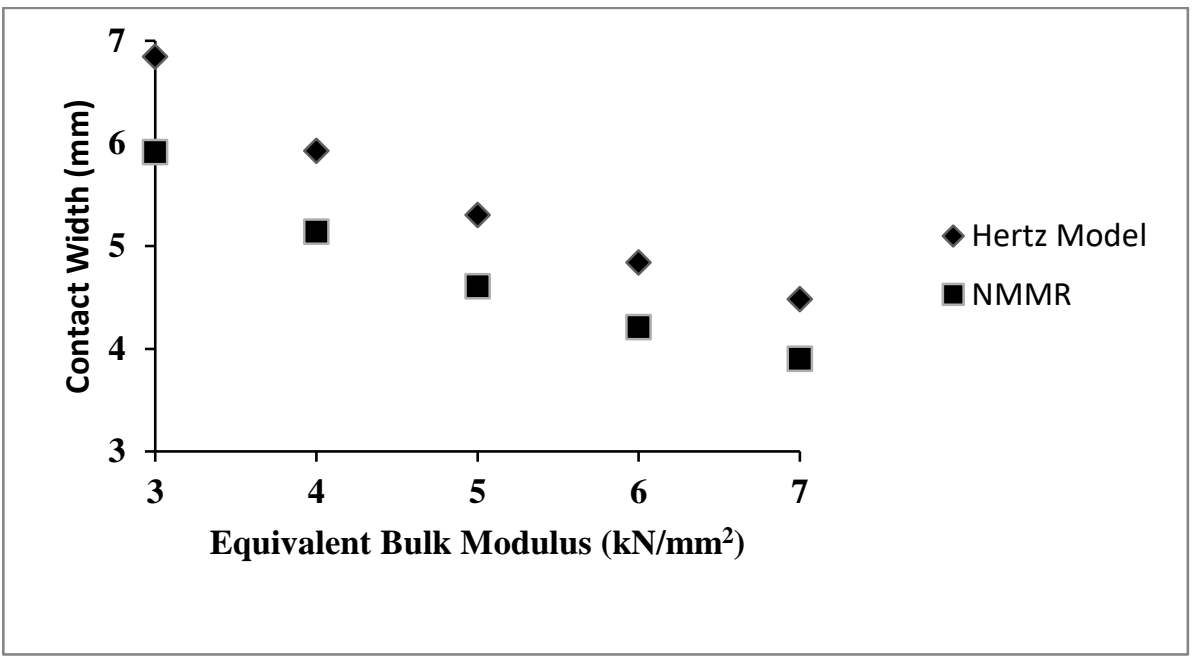

Fig. 4. Impact of equivalent bulk modulus on contact width

\subsection{Impact of cover thickness on contact width}

The contact width $A$ is computed for various estimations of cover thickness with the constant load applied $0.263 \mathrm{kN} / \mathrm{mm}$ by utilizing equation (16), whereas keeping other parameters constant as shown in Table 4 and the graph is plotted for different values as appeared in Figure 4.

It demonstrates that with increase in cover thickness and continuing residual parameters constant, contact width increases. The results obtained from the Hertz model is compared with the results obtained by nip mechanics model for rolling calender (NMMR). It is found that there is a huge difference between the results obtained from NMMR and Hertz model because NMMR considered the cover thickness of soft roll while Hertz Model does not take it into account. With the increase in cover thickness, contact width also increases. Hence, gloss and smoothness of fabric increase with increase in cover thickness.

\begin{tabular}{ccc}
\hline Cover thickness $(\mathbf{m m})$ & $\begin{array}{c}\text { Hertz model based } \\
\text { contact width } \\
(\mathbf{m m})\end{array}$ & $\begin{array}{c}\text { NMMR based } \\
\text { contact width } \\
(\mathbf{m m})\end{array}$ \\
\hline $\mathbf{1 0}$ & 6.7028 & 6.3943 \\
$\mathbf{1 1}$ & 6.7028 & 6.4403 \\
$\mathbf{1 2}$ & 6.7028 & 6.477 \\
$\mathbf{1 3}$ & 6.7028 & 6.5065 \\
$\mathbf{1 5}$ & 6.7028 & 6.531 \\
\hline
\end{tabular}

Table 4. Contact width for different values of cover thickness 


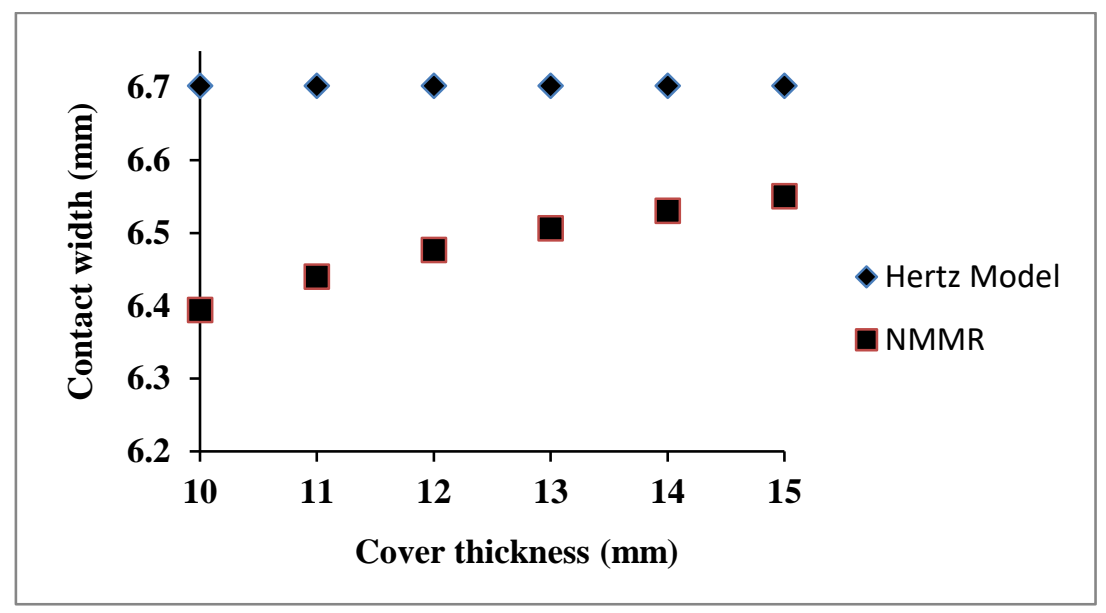

Fig. 5. Impact of cover thickness on contact width

\section{The applicability of the NMMR model to the textile industry}

Hertz model can only be applied to machine calenders as he didn't consider the cover thickness of the soft roll. The solution given by Meijers cannot be applied directly for the calendering process because of his consideration of contact width as $2 c$ and presenting the results in a nondimensional form. Deshpande model is only applicable for cylinders with covering of incompressible material. The NMMR model developed in this present investigation is an extension of Hertz and modification of Meijers which can be suitably used for textile calendering. With the help of model developed, rolling calender can be designed according to the nature of texture required, as contact width acts as an imperative part in influencing eminence of texture.

\section{Conclusion}

The model created in this analysis is a comprehensive model. This model is significant to textile manufacturing and beating the inconveniences adjusted by Hertz and Meijers models. The model is an augmentation of the Hertz model and enhancement of Meijers model. The impact of design and process parameters on contact width has been scrutinized and the eventual outcomes of the present model are contrasted with the outcomes acquired by Hertz model. From the analysis of the model it is found that the NMMR gives better results as compared to conventional models for acquiring gloss and smoothness. This NMMR model helps to obtain a fabric with better gloss and smoothness because cover thickness plays crucial role in calendering process which is considered in this model.

\section{References}

Bhat GS, Jangala PK, and Spruiell JE (2004). Thermal bonding of polypropylene nonwovens: effect of bonding variables on the structure and properties of the fabrics, Journal of Applied Polymer Science, 92, 3593-3600.

Callister WD (2007). Materials science and engineering-an introduction, John Wiley \& Sons. 
Darji PH and Vakharia DP (2013). Evaluation of contact width for elastic hollow cylinder and flat contact through experimental technique and extending the capabilities of Hertz equation, International Journal of Surface Science and Engineering.

Deshpande NV (1978). Calculation of Nip Width, Penetration and Pressure for Contact between Cylinder with Elastomeric Covering, Tappi, 61, 115.

Dintwa E, Tijskens E, and Ramon H (2008). On the accuracy of the Hertz model to describe the normal contact of soft elastic spheres, Granular Matter, 10, 209-221.

Enomae T, Huang T, and LePoutre P (1997). Softcalendering: Effect of temperature, pressure and speed on sheet properties, Nordic Pulp and Paper Research Journal, 12, 13-18.

Fu G (2007). An extension of Hertz's theory in contact mechanics, Journal of applied mechanics, $74,373-374$.

Hall AJ (1966). Textile finishing, London : Heywood Books, an imprint of Iliffe Books.

Johnson KL (1982). One hundred years of Hertz contact, Proceedings of the Institution of Mechanical Engineers, 196, 363-378.

Johnson KL (1985). Contact Mechanics, 1st, Cambridge: Cambridge University Press.

Jokio M (1999). Papermaking Science and Technology, Papermaking Part 3, Finishing, Helsinki, Fapet Oy, 1999, ISBN 952-5216-10-1.

Kanth N, Ray AK, and Dang R (2016). Effect of design and process parameters on nip width of soft calendering, International Journal for Computational Methods in Engineering Science and Mechanics, 17, 247-252.

Kanth N, Ray AK, and Riti (2014). Mathematical model to investigate the effect of design and process parameters on nip width of supercalender, International Journal of Modeling, Simulation, and Scientific Computing, 5, 1450020.

Kogut L, and Etsion I. (2002). Elastic-plastic contact analysis of a sphere and a rigid flat, Journal of applied Mechanics, 69, 657-662.

Kopitar D, Skenderi Z, and Rukavina T. (2014). Impact of calendering process on nonwoven geotextiles hydraulic properties. Textile research journal, 84, 66-77.

Liu S, Peyronnel A, Wang QJ, and Keer LM (2005). An extension of the Hertz theory for 2D coated components, Tribology Letters, 18, 505-511.

Mahmoud FF, El-Shafei AG, Attia MA and Rahman AA (2013). Analysis of quasistatic frictional contact problems in nonlinear viscoelasticity with large deformations, International journal of mechanical sciences, 66, 109-119.

Meijers P (1968). The contact problem of a rigid cylinder on an elastic layer, Applied Scientific Research, 18, 353-383.

Naghieh GR, Rahnejat H, and Jin ZM (1999). Characteristics of frictionless contact of bonded elastic and viscoelastic layered solids, Wear, 232, 243-249.

Osswald T and Hernández-Ortiz JP (2006). Polymer processing, Modeling and Simulation. Munich: Hanser, 1-651.

Peel JD (1991). Supercalendering and soft nip calendering compared, Tappi journal, 74, 179186.

Rodal JJ (1989). Soft-nip calendering of paper and paperboard, Tappi journal, 72, 177-186.

Solanki MT and Vakharia D (2017a). A finite element analysis of an elastic contact between a layered cylindrical hollow roller and flat contact, Industrial Lubrication and Tribology, 69, $30-41$.

Solanki MT and Vakharia D (2017b). Extending Hertz equation for an elastic contact between a layered cylindrical hollow roller and flat plate through an experimental technique, Industrial Lubrication and Tribology, 69, 312-324.

Sorvari J and Parola M (2014). Feeding in rolling contact of layered printing cylinders, International Journal of Mechanical Sciences, 88, 82-92.

Zhu H, He Z, Jiang H, and Ma S (2018). Experimental investigation into the failure mechanism of ductile line contact structures, Mechanics of Materials. 
Appendix A

Design and process parameters

\begin{tabular}{|c|c|c|}
\hline Parameters & Rolling calender & Data used for Simulation \\
\hline Composition & $\begin{array}{l}\text { Alternate hard and soft roll } \\
\text { nips }\end{array}$ & $\begin{array}{l}\text { One nip (Top roll hard and } \\
\text { bottom roll soft) }\end{array}$ \\
\hline Hard roll material & $\begin{array}{l}\text { Steel cylinders having a } \\
\text { covering of chilled cast iron }\end{array}$ & $\begin{array}{l}\text { Bulk modulus and Poison's Ratio } \\
E_{1}=140 \mathrm{kN} / \mathrm{mm}^{2} \\
v_{1}=0.28\end{array}$ \\
\hline Soft roll material & $\begin{array}{l}\text { Steel cylinders having a } \\
\text { covering of compressed long } \\
\text { fiber cotton }\end{array}$ & $\begin{array}{l}\text { Bulk modulus and Poison's Ratio } \\
E_{2}=2.41 \mathrm{kN} / \mathrm{mm}^{2} \\
v_{2}=0.48\end{array}$ \\
\hline Contact width(A) & $5-15 \mathrm{~mm}$ & Computed by model \\
\hline $\begin{array}{l}\text { Thickness of white iron } \\
\text { (cover thickness) }\end{array}$ & $10-15 \mathrm{~mm}$ & $10 \mathrm{~mm}$ \\
\hline $\begin{array}{l}\text { Thickness of soft } \\
\operatorname{cover}(t)\end{array}$ & $10-20 \mathrm{~mm}$ & $17 \mathrm{~mm}$ \\
\hline Diameter of roll & $450-1000 \mathrm{~mm}$ & $300 \mathrm{~mm}, 700 \mathrm{~mm}$ \\
\hline
\end{tabular}

Appendix B

Nomenclature

\begin{tabular}{ll}
\hline Table & Notation \\
\hline$A$ & Contact Width \\
$L$ & Load Applied \\
$D_{1}$ & The diameter of cylindrical roll I \\
$D_{2}$ & The diameter of cylindrical roll II \\
$D_{E}$ & Equivalent Diameter \\
$E_{1}$ & Bulk Modulus of cylinder roll I \\
$E_{2}$ & Bulk Modulus of cylinder roll II \\
\hline
\end{tabular}




\begin{tabular}{ll}
\hline$E^{*}$ & Equivalent Bulk Modulus \\
$v_{1}$ & Poisson Ratio of cylinder roll I \\
$v_{2}$ & Poisson Ratio of cylinder roll II \\
$t$ & Cover Thickness of soft cover \\
\hline
\end{tabular}

